\title{
OS CADERNOS PEDAGÓGICOS NO PROGRAMA NOSSA REDE: Uma proposta curricular de dimensão intercultural para as escolas públicas de Salvador-BA
}

\author{
Ana Cristina Santos Peixoto ${ }^{1}$ \\ Rossimara Inês Ferreira da Cunha²
}

\section{RESUMO}

A identidade de um povo é um dos fatores imprescindíveis para o desenvolvimento e aprimoramento da educação. Com foco nessa premissa, o Programa Nossa Rede em parceria com a Secretaria Municipal da Educação (SMED) de Salvador, estado da Bahia, e o Instituto Chapada de Educação e Pesquisa (ICEP) propõem novas diretrizes curriculares para os anos iniciais do Ensino Fundamental I, por meio do uso de Cadernos Pedagógicos que valorizem as identidades culturais de Salvador e suas peculiaridades. Este estudo tem como objetivo avaliar o impacto da implantação do Programa Nossa Rede no que tange à ampliação dos conteúdos programáticos comuns a cada área do conhecimento e ano de escolaridade, cujas estruturas cognitivas e atividades experienciais concebam uma proposta curricular de dimensão intercultural que contribua para as crianças aprender de maneira prazerosa, crítica e significativa. Os procedimentos técnicos utilizados para a obtenção das informações foram a pesquisa bibliográfica e a pesquisa-ação, com enfoque qualitativo. A pesquisa bibliográfica foi realizada com base em livros, leis, teses, dissertações, artigos científicos, acesso a sites validados, e outros. A pesquisa-ação foi fundamentada em documentos pertinentes a este estudo e nos depoimentos registrados durante a realização de seminários e eventos ocasionais, proferidos por alguns renomados doutrinadores, os quais contribuíram para a construção coletiva dos Marcos de Aprendizagem de Língua Portuguesa, Matemática, História, Geografia e Ciências, e para a produção dos Cadernos Pedagógicos de Língua Portuguesa e Matemática.. Os resultados discutidos neste estudo ampliam a capacidade de compreensão dos professores acerca de suas práticas pedagógicas, favorecendo amplamente às mudanças dada a flexibilidade do currículo, e promovendo a visão de conjunto para a tomada de consciência de todos os envolvidos. Conclui-se que através da articulação entre gestores, coordenadores pedagógicos e professores na discussão do planejamento, objetivos, expectativas e metas a serem alcançadas, o currículo das escolas municipais de Salvador possa atingir o objetivo maior da educação que é a formação integral do ser humano. Educar pressupõe transformar-se.

Palavras-chave: Currículo Intercultural. Ensino Fundamental. Cadernos Pedagógicos. Relações Étnico-Raciais.

\section{ABSTRACT}

The identity of a people is one of the essential factors for the development and improvement of education. Focused on this premise, the Nossa Rede Program in partnership with the Municipal Education Secretariat (SMED) of Salvador, state of Bahia, and the Chapada Institute of Education and Research (ICEP) propose new curricular guidelines for the early years of Elementary School I, through the use of Pedagogical Notebooks that value the cultural identities of Salvador and its peculiarities. This study aims to evaluate the impact of the implantation of the Nossa Rede Program regarding the expansion of the syllabus contents common to each area of knowledge and school year, whose cognitive structures and experiential activities conceive a curricular proposal with an intercultural dimension that contributes to the children learn in a pleasurable, critical and meaningful way. The technical procedures used to obtain the information were bibliographic research and action research, with a qualitative focus. The bibliographic research was carried out based on books, laws, theses, dissertations, scientific articles, access to validated sites, and others. The action research was

\footnotetext{
${ }^{1}$ Mestra em Ciências da Educação pela Facultad Interamericana de Ciencias Sociales. Coordenadora Pedagógica da Rede de Ensino Municipal de Salvador.

${ }^{2}$ Mestra em Ciências da Educação pela Facultad Interamericana de Ciencias Sociales. Professora do Ensino Fundamental e da Educação de Jovens e Adultos da Rede de Ensino Municipal de Salvador.
} 
based on documents pertinent to this study and on the testimonies recorded during seminars and occasional events, given by some renowned doctrines, which contributed to the collective construction of the Portuguese Language Learning Mathematics, Mathematics, History, Geography and Sciences, and for the production of the Pedagogical Notebooks of Portuguese Language and Mathematics. The results discussed in this study expand the teachers' ability to understand their pedagogical practices, largely favoring the changes given the flexibility of the curriculum, and promoting the overall vision for the awareness of all involved.It is concluded that through the articulation between managers, pedagogical coordinators and teachers in the discussion of the planning, objectives, expectations and goals to be achieved, the curriculum of the municipal schools of Salvador can reach the major objective of education which is the integral formation of the human being. Educating presupposes transformation.

Keywords: Intercultural Curriculum. Elementary School. Pedagogical Notebooks. Ethnic-Racial Relations.

\section{INTRODUÇÃO}

O tema delimitado neste estudo trata da aplicabilidade dos Cadernos Pedagógicos, discutidos e elaborados no Projeto 'Nossa Rede', como proposta curricular de dimensão intercultural, alinhando uma linguagem comum em todas as escolas públicas de Salvador (BA) do Ensino Fundamental, a partir dos conteúdos programáticos estabelecidos para cada ano de escolaridade, visando o desenvolvimento integral desse público infantil.

A educação que se pretende oferecer às crianças do $1^{\circ}$ ao $5^{\circ}$ ano do Ensino Fundamental I, sujeitos envolvidos no contexto desta pesquisa, está fundamentada na missão da Secretaria Municipal de Educação (SMED) do estado da Bahia, que visa promover educação básica de qualidade, garantindo acesso à cultura, esporte $e$ lazer, contribuindo para a formação do cidadão e sua inclusão social.

O que norteou a pesquisa e motivou a construção deste artigo foi a produção e implementação dos Cadernos Pedagógicos, como marcos norteadores do currículo da Rede Municipal de Educação de Salvador, cuja proposta de planejamento das atividades de ensino pode propiciar uma aprendizagem significativa, que favoreça o desenvolvimento das competências e habilidades dos alunos nas diversas áreas do conhecimento.

A escola, enquanto espaço social e formal onde circula uma multiplicidade de saberes é o local ideal para a socialização e inclusão de todos, independente das diversas origens, nacionalidade, religião, etnias, convergindo para a viabilidade de identidades plurais, o que implica na integração social entre todas as crianças.

O Nossa Rede, Projeto Pedagógico de Salvador, busca respeitar essa diversidade e desenvolver os Cadernos Pedagógicos a partir da cultura local de Salvador, utilizando textos e gravuras que tenham informações sobre a riqueza e 
diversidade da nossa cidade. Com a parceria da Secretaria Municipal da Educação (SMED) e do Instituto Chapada de Educação e Pesquisa (ICEP), o Nossa Rede vem ajudando dezenas de municípios baianos a melhorarem os Índices de Educação Básica (IDEB), especialmente na Chapada Diamantina, onde foi criado.

$\mathrm{Na}$ tentativa de apreender a importância do uso dos Cadernos Pedagógicos no processo de escolarização, infere-se a seguinte hipótese: "O envolvimento e participação de todos no Projeto Pedagógico de Salvador 'Nossa Rede' possibilitará condições ainda melhores para a aplicação/transmissão dos conteúdos, enriquecendo o trabalho dos docentes e, consequentemente, o processo de aprendizagem dos estudantes".

A relevância deste estudo consiste na valorização da cultura local inserida no currículo escolar e na prioridade do entendimento de mundo trazido pelos alunos. A transmissão cultural promovida pela escola aliada ao conhecimento prévio é fundamental para formar crianças, no sentido de que adquiram capacidade de questionar, de se posicionar ativamente, de se transformar, e assim construir sua própria trajetória.

Visando melhoria no processo ensino-aprendizagem suscita-se como problemática desta pesquisa a seguinte questão: "Quais propostas pedagógicas de dimensão intercultural ancoram o trabalho desenvolvido pelos educadores da rede municipal de Salvador a partir do uso dos Cadernos Pedagógicos?".

Com o propósito de buscar respostas para tal questionamento, o objetivo geral deste trabalho consiste em avaliar o impacto da implantação do Programa Nossa Rede no que tange à ampliação dos conteúdos programáticos comuns a cada área do conhecimento e ano de escolaridade, cujas estruturas cognitivas e atividades experienciais concebam uma proposta curricular de dimensão intercultural que contribua para as crianças aprenderem de maneira prazerosa, crítica e significativa.

Este trabalho está estruturado desta Introdução; do Referencial Curricular Municipal para a Educação Infantil de Salvador; do Percurso Metodológico da Pesquisa-Ação; dos Resultados e Discussão; das Considerações Finais; além das Referências Bibliográficas.

2 O REFERENCIAL CURRICULAR MUNICIPAL PARA A EDUCAÇÃO INFANTIL DE SALVADOR 
Para subsidiar a fundamentação teórica sobre a elaboração do Referencial Curricular Municipal para a Educação Infantil de Salvador discorre-se sobre quatro importantes temáticas: Nossa Rede: Projeto Pedagógico de Salvador; Contribuições de doutrinadores para a elaboração da proposta curricular; A proposta curricular de dimensão intercultural do Nossa Rede; Os Cadernos Pedagógicos de Matemática e Língua Portuguesa.

\subsection{Nossa Rede: Projeto Pedagógico de Salvador}

O Nossa Rede é um Projeto Pedagógico de Salvador, pioneiro na educação pública brasileira, que tem por objetivo a elaboração das novas Diretrizes Curriculares da Educação Infantil e do Ensino Fundamental, com foco na participação e criação colaborativa, dentro de uma visão de respeito aos valores das identidades culturais de Salvador e suas peculiaridades. O processo de criação do referido Projeto contou com o apoio de parceiros como a Avante - Educação e Mobilização Social, do Instituto Chapada de Educação e Pesquisa (ICEP) e da Associação Pracatum Ação Social (APAS).

Previsto no Programa Combinado por uma escola melhor, da Secretaria Municipal da Educação (SMED), o Nossa Rede foi lançado oficialmente pela Prefeitura de Salvador, no dia 30 de junho de 2015, norteado pelos princípios da gestão democrática e participativa e pela legislação vigente: Lei de Diretrizes e Bases (BRASIL, 1996), Diretrizes Curriculares Nacionais (BRASIL, 2013) e Plano Municipal da Educação (PME, 2010).

A realização desta ação faz parte do Programa Combinado, da Secretaria Municipal da Educação (SMED), que reúne um conjunto de 112 ações concretas e diretamente mensuráveis a serem realizadas em parceria entre a Prefeitura e a comunidade escolar, representada pelos professores, funcionários, alunos e pais de alunos. Dentre as 112 ações previstas destaca-se no contexto deste estudo a de número 9: Elaborar/Revisar e implementar as novas diretrizes curriculares municipais e o material didático de Língua Portuguesa e Matemática para o Ensino Fundamental I, em regime colaborativo com representantes da Rede.

Para a sistematização dos objetivos, conteúdos e situações didáticas que contemplem o alcance das competências e habilidades desta proposta curricular, o Projeto Pedagógico de Salvador tem como parâmetros os Marcos de Referência da Secretaria Municipal de Educação e Cultura (SMEC); as Diretrizes Curriculares 
Nacionais para a Inclusão da História e Cultura Afro-Brasileira e Indígena; e as Diretrizes da Educação Ambiental.

O Currículo expressa o Projeto Político Pedagógico da escola, organiza a práxis educativa, considerando as especificidades do aluno, da sociedade e da cultura, cabendo à escola decidir sobre projetos que podem ser desenvolvidos. As experiências a serem trabalhadas devem ser baseadas em diversos critérios de ordem social, política, cultural, filosófica e econômica.

Os conteúdos das diferentes áreas de ensino irão propiciar ao aluno o desenvolvimento de capacidades intelectuais, o pensamento autônomo, a construção da própria identidade e a consciência, participando ativamente da vida social, através de uma ação pedagógica que não esteja restrita somente ao conteúdo e aos seus conhecimentos prévios, despertando, sobretudo, a curiosidade, o questionamento e a reflexão.

Nessa perspectiva, o Nossa Rede traz os elementos da cidade de Salvador, como a cultura, a arte e a diversidade, que fazem parte da vida do aluno, para serem trabalhados em sala de aula, apregoando que não pode haver dissonância em relação à aprendizagem entre as instâncias regionais. Alinhar concepções é imprescindível. Morar na mesma região, no mesmo espaço geográfico, implica ter uma mesma relação de conhecimento, fortalecendo os saberes da escola.

Participaram desta proposta curricular o Grupo de Trabalho Institucional (GTI) formado por representantes da Diretoria Pedagógica da SMED; Coordenadoras Pedagógicas; equipe do ICEP; equipe de coordenação das áreas de Língua Portuguesa e Matemática; equipe de edição e editoração, com a função estratégica de gestão e alinhamento do Projeto; e os Grupos de Trabalhos Regionais (GTRs) que reúnem representantes de professores, coordenadores pedagógicos e gestores escolares, em regime colaborativo, para debater e contribuir na construção dos conteúdos das Diretrizes Curriculares do Ensino Fundamental, bem como da produção dos Cadernos Pedagógicos, durante os encontros realizados nas 10 gerências regionais.

O Nossa Rede contou com a assessoria do Instituto Chapada de Educação e Pesquisa (ICEP), uma Organização da Sociedade Civil de Interesse Público (OSCIP), brasileira, fundada em 2006, sem fins lucrativos, com a missão de melhorar a aprendizagem de alunos da Educação Infantil e do Ensino Fundamental. Para isso promove a formação de gestores escolares, coordenadores pedagógicos e equipes técnicas das secretarias de Educação, tornando-se uma instituição de 
referência no trabalho em redes colaborativas, que envolve pais, estudantes e representantes da sociedade civil.

Para viabilizar a participação de todos os sujeitos da Educação na construção deste Projeto Pedagógico foi criada uma plataforma virtual denominada Plataforma Colaborativa, ${ }^{3}$ na qual os gestores apresentarão as demandas das escolas e serão respondidos pelas instâncias públicas de educação, possibilitando avaliação imediata dos problemas que atingem a rede, o que, com certeza, provocará um impacto na qualidade da educação.

O ambiente virtual do Nossa Rede viabiliza a participação de todos os sujeitos da Educação na construção desta proposta curricular, que poderão ver, analisar, comentar e contribuir com a elaboração de todos os materiais que serão coletivamente sistematizados nos GTIs (Grupos de Trabalho Institucional) e GTRs (Grupos de Trabalho Regionais); incluir sugestões que tornem os materiais o mais próximo possível da realidade local; e listar recursos da cultura de Salvador que possam ser agregados aos projetos, como textos de poetas, brincadeiras, grupos musicais, artistas, aspectos ambientais, costumes locais, entre outros.

No âmbito da escola, a Coordenação Pedagógica deverá subsidiar o papel do professor para que institucionalmente se alinhe às práticas pedagógicas que fundamentam o currículo escolar. O professor deve ser o mediador, pois para a construção de saberes e conhecimentos é necessário uma prática reflexiva, que induza os educandos a organizar e decidir regras de convivência, ser capaz de planejar, avaliar ações e o seu próprio desempenho.

Há um provérbio africano que diz: "É preciso uma aldeia inteira para educar uma criança". Com base nessa expressão popular pressupõe-se o envolvimento e responsabilidade de toda a sociedade na formação das novas gerações. Os GTI e os GTRs têm contribuído nesse sentido no processo de elaboração da proposta curricular das escolas públicas de Salvador.

\subsection{Contribuições de doutrinadores para a elaboração da proposta curricular}

Vive-se em um mundo complexo, que não pode ser completamente explicado por um único ângulo, mas a partir de uma visão multifacetada, construída

\footnotetext{
${ }^{3}$ Site da Plataforma Colaborativa <http://educacao.salvador.ba.gov.br/sistema/nossa-rede-plataformacolaborativa>
} 
pelas visões das diversas áreas do conhecimento. Desse modo, presume-se que a organização do Currículo, projetada nas possibilidades e limites para a elaboração dos Cadernos Pedagógicos do Nossa Rede, deve procurar viabilizar uma maior interdisciplinaridade, contextualização e transdisciplinaridade, assegurando a livre comunicação entre todas as áreas.

A possibilidade de elaborar uma proposta curricular que projete a escola como lugar de construção de conhecimento e do aluno como sujeito desse processo foi estabelecida pelas contribuições de diversos doutrinadores, abaixo referenciadas.

O debate sobre a valorização da cultura escolar está contido na obra História das disciplinas escolares: reflexões sobre um campo de pesquisa (1990), do historiador francês André Chervel (1931), quando fala da capacidade da escola produzir uma cultura específica, singular e original. Chervel critica os esquemas explicativos que posicionam a noção da escola como simples agente de transmissão de saberes, elaborados fora dela, lugar, portanto, do conservadorismo, da rotina e da inércia. Para ele, a instituição escolar é capaz de produzir um saber específico, cujos efeitos estendem-se sobre a sociedade e a cultura, e que emerge das determinantes do próprio funcionamento institucional. A proposta do currículo escolar é uma importante ferramenta teórica para explorar a relação da escola com a sociedade e a cultura, no jogo tenso das lutas de poder que perpassam o próprio ambiente escolar e nele expressam as mais diversas contradições sociais.

O norte-americano David Ausubel (1918-2008), especialista em Psicologia Educacional, comenta no seu livro "A Aprendizagem Significativa" (1982) que o conhecimento prévio é a variável que influencia, por excelência, a real aprendizagem dos alunos. Aprender significativamente é ampliar e reconfigurar ideias já existentes na estrutura mental e com isso ser capaz de relacionar e acessar novos conteúdos. Este idealizador do conceito de aprendizagem significativa prevê a necessidade de o aprendiz se colocar como sujeito ativo e não passivo em seu processo de aprendizagem, e enfatiza a necessidade de não se transformar diferenças sociais, econômicas, culturais e cognitivas em desigualdades escolares.

Autores como Novak e Gowin afirmam em no texto "Aprender a aprender" (1996) que a experiência de ensinar e aprender pressupõe troca de significados e sentimentos, portanto, o desejo de aprender. Gowin propõe uma relação - como uma negociação - entre professor e aluno envolvendo os materiais educativos com o objetivo específico de compartilhamento de significados. Neste cenário, o papel do 
professor enquanto mediador na evolução da aprendizagem dos alunos é de suma importância.

O livro "A Formação Social da Mente" (1998), da autoria do psicólogo russo Lev Semyonovich Vygotsky (1896-1934), enfoca a interação social enquanto veículo fundamental para a transmissão dinâmica do conhecimento, o que implica um mínimo de duas pessoas intercambiando significados. Vygotsky foi pioneiro no conceito de que o desenvolvimento intelectual das crianças ocorre em função das interações sociais e condições de vida. Nesse contexto, o professor é figura essencial do saber por representar um elo intermediário entre o aluno e o conhecimento disponível no ambiente.

Para Paulo Freire, em sua obra Pedagogia do Oprimido (2011), revisada e atualizada, o fim maior da educação deve ser desenvolvido a partir do diálogo e da consciência, permitindo às pessoas lutar por sua liberdade, contra a máquina opressora do capitalismo. Para este educador, toda aprendizagem é transformadora e acontece nas modalidades formal e informal, através de uma ação plena de reflexão crítica do aluno e do professor, com embasamento na prática e na ação de suas próprias experiências e de sua interação com o meio social.

Neste sentido, o educando torna-se competente quando exerce a construção de sua aprendizagem, com o propósito de transformar a si próprio, edificando sua alteridade e compreendendo sua identidade. Portanto, a aprendizagem transformadora possibilita que o aluno, aprenda a ser, a viver, a conviver, a conhecer e a fazer, aprendendo a construir e compartilhar.

A sociedade atual exige sujeitos alfabetizados, letrados, competentes em relação à compreensão do mundo, à leitura e à escrita, sabendo usá-las nas mais diversas situações. Desse modo, a educação formal é o instrumento que vai permitir a busca por uma melhoria de vida, bem como a capacitação para competir no mercado de trabalho. Presume-se assim que investir na educação é investir no futuro de cada ser humano, e por extensão, no desenvolvimento do país.

\subsection{A proposta curricular de dimensão intercultural do Nossa Rede}

A Base Nacional Comum Curricular (BNCC), prevista pelo Plano Nacional de Educação (PNE), dá as diretrizes para orientar a elaboração dos currículos das redes municipais, estaduais e federal. De acordo com o Ministério da Educação 
(MEC), todas as escolas públicas e particulares devem adotar novas referências para seus currículos até início do ano letivo de 2020.

Nessa perspectiva, a nova BNCC para os ensinos infantil e fundamental foi aprovada no dia 15 de dezembro de 2017, em votação no Conselho Nacional de Educação (CNE). Vale destacar que Salvador é um dos primeiros municípios do Brasil a ter o seu currículo adequado às novas diretrizes da BNCC, homologada pelo Ministério da Educação (MEC), no dia 20 de dezembro de 2017.

Estruturar um currículo por áreas de conhecimento significa colocá-las em diálogo permanente, conforme as afinidades entre elas e os objetivos de aprendizagem, o que implica uma agenda programática de ações para serem construídas e desenvolvidas com as escolas. Assim, buscou-se construir um documento referencial e materiais pedagógicos que provocassem nexos e permitissem a estruturação de um ensino que se articule com a realidade local e se aproxime de outras realidades no tempo e nos espaços, por meio das variadas áreas de conhecimento.

O Referencial Curricular da Educação Infantil de Salvador representa um guia para a construção de propostas pedagógicas nas instituições de Educação Infantil e para as rotinas de cada professor. Foi elaborado entre os anos 2014 e 2015, contando com a representação de professores, coordenadores pedagógicos, gestores e equipes das Gerências Regionais de Educação (GREs) e Secretaria da Educação, em diversos espaços de discussão e validação, assim como com a reflexão permanente das práticas.

O processo de construção desse documento pauta-se no compromisso com a construção coletiva, no respeito ao conhecimento teórico e prático dos profissionais que atuam com as crianças e no desejo de avançar. Sistematizado a partir de uma parceria técnica com a Avante - Educação e Mobilização Social revela o momento da Rede, suas demandas específicas e sua visão sobre uma educação para a infância possível, neste contexto socio-histórico e educacional.

A intencionalidade deste Referencial Curricular é tornar a instituição de Educação Infantil uma comunidade aprendente, cujas atividades cotidianas sejam analisadas criticamente, constituindo-se em objeto de estudo e de curiosidade pelo coletivo de professores e, no interjogo teoria e prática, possam ser revistas e reformuladas sempre que se fizer necessário. A análise, os questionamentos, o estudo, devem partir do compromisso com a criação de igualdade de oportunidades para todas as crianças. 
Salvador é conhecida como a "cidade mais negra do Brasil" por concentrar a maior comunidade de negros fora do continente africano, construída desde a época do Brasil Colônia, a partir do trabalho de escravizados nos engenhos de açúcar do Recôncavo Baiano. O Instituto Brasileiro de Geografia e Estatística aponta que, em 2018, uma em cada 5 pessoas na Bahia se declara preta. Os dados são da Pesquisa Nacional por Amostra de Domicílios Contínua (PNAD Contínua), divulgada no dia 22 de 2019, no portal globo.com.

Considerando esta configuração da população baiana, o debate referente às relações étnico-raciais e da história e cultura africanas e afro-brasileiras, previsto na Lei 10.639, de 9 de janeiro de 2003, impulsiona mudanças significativas nas escola básica da cidade de Salvador, articulando o respeito e o reconhecimento à diversidade étnico-racial com a qualidade social da educação. Vale ressaltar que grupos humanos não são marcados por características biológicas, mas, sim, por processos históricos e culturais.

O foco na pluralidade cultural pode contribuir para a desconstrução de discursos etnocêntricos. Ainda hoje na escola, tanto em nível das práticas institucionais como no das relações entre professores e alunos, a criança negra e afrodescendente parece ainda experimentar situações de real desvantagem em relação às demais. A discriminação racial sempre foi e ainda é um fato no Brasil.

Entende-se que partes significativas das desigualdades raciais entre brancos e negros vinculam-se à discriminação racial existente tanto na escola como no mercado de trabalho e que são determinadas, em grande medida, pela desinformação, além do desinteresse. Nesse entorno, enquanto um trabalhador cultural, o docente pode desenvolver um discurso que una a linguagem da crítica e da possibilidade capaz de promover mudanças na escola, assumindo a necessidade de dar voz ativa aos seus alunos, manifestando-se, sobretudo, contra todas as formas de discriminação e injustiça.

Um dos objetivos centrais da proposta curricular da Rede Municipal de Salvador é formar pessoas capazes de raciocinar, analisar, deduzir, criar, resolver situações e buscar estratégias inovadoras. A pretensão desta política estratégica de educação consiste em ter alunos preparados para enfrentar o mundo em constante transformação.

Um marco histórico importante foi a construção do documento Diretrizes Curriculares para a Inclusão da História e Cultura Afro-Brasileira e Africana no Sistema Municipal de Ensino de Salvador, da Secretaria da Educação e Cultura. 
Como ação complementar, a SMEC constituiu uma assessoria técnica para, junto às escolas, analisar o referido documento, por meio de um instrumento de avaliação da efetividade e adequação às propostas de educação municipal.

Ressalta-se também a Resolução 033 do Conselho Municipal de Educação (CME), publicada no dia 4 de dezembro de 2015, que estabelece as Diretrizes Curriculares Municipais para Educação Escolar Quilombola, do Sistema Municipal de Ensino de Salvador para subsidiar as escolas inseridas em comunidades remanescentes de quilombos e as que recebem estudantes oriundos dessas comunidades.

A proposta didático-pedagógica do Nossa Rede baseia-se numa educação que garanta uma aprendizagem significativa, crítico e reflexiva, a partir das experiências e vivências do dia a dia, relacionando-as aos conteúdos da disciplina, garantindo a aproximação da realidade com a própria condição do sujeito histórico que é a criança; o desenvolvimento da competência leitora, muito além do exclusivamente instrumental, como aspecto da formação educacional do estudante; a produção escrita e a oralidade desenvolvidas em textos e contextos com atividades voltadas para o desenvolvimento dessas competências; e o exercício da cidadania veiculada no ensino de História por uma formação voltada para a ética e a reflexão crítica e atuante no mundo moderno.

O Nossa Rede propõe a articulação entre as ideias sistematizadas neste documento com as sequências didáticas organizadas nos Cadernos Pedagógicos, os saberes dos professores e estudantes, as especificidades e os projetos de cada escola, e os espaços de formação. Com isso, há a possibilidade de mudança na organização do trabalho pedagógico, na concepção, crenças e posturas de educadores e estudantes. Isso implica, ainda, espaços de vivência e diálogo entre todos os envolvidos no processo educativo para assegurar a ruptura com as práticas pedagógicas fragmentadas e descontextualizadas.

Propõe-se, portanto, um currículo que priorize a problematização e a investigação por meio de um trabalho coletivo, que rompa as fronteiras das várias áreas do conhecimento respeitando, simultaneamente, a especificidade de cada disciplina e de cada ano do ensino. É preciso que haja o equilíbrio necessário à integração, à articulação e ao entrelaçamento entre todos os saberes.

Neste sentido, é imprescindível compreender a forma como diferentes sujeitos expressam seus preconceitos e estereótipos e como essas disposições atitudinais podem refletir-se nas relações entre os componentes da escola. A 
reflexão deve alcançar também aquelas estabelecidas no processo de ensino entre os sujeitos e os novos conhecimentos construídos.

Orientados pelo trabalho eficiente do grupo gestor, os educadores devem planejar aulas interessantes, com atividades lúdicas e brincadeiras que visam o desenvolvimento do corpo e da mente. É importante também trabalhar com textos significativos para as crianças, especialmente histórias da literatura infantil, a fim de que elas se envolvam e gostem de participar das atividades de leitura, no sentido de se tornarem conhecedoras da realidade, formadoras de suas próprias ideias e assim contribuírem para a construção de sua própria história e da história do meio onde vivem.

Telma Weisz, uma das autoras dos Parâmetros Curriculares Nacionais (PCN) de Língua Portuguesa, defende que os modelos de currículo devem estar vinculados a uma orientação didática. Dessa forma, assim ponderou:

Se queremos formar crianças que tenham capacidade de transformar, de
questionar, de se portar ativamente, de criar sua própria trajetória é
fundamental estimular novos modos de pensar a produção cultural, e não
reproduzir conceitos mecanicamente. O que eu lhes diria é que precisamos
discutir os sentidos formativos. E também temos que discutir muito sobre
'para que mandamos as crianças às escolas', e'o que queremos que elas
aprendam' (NOSSA REDE, 2017, [s.p]).

As crianças devem se deparar com situações do cotidiano, identificar-se com os sujeitos e fatos históricos, e pensar a memória como aspecto fundamental das temporalidades a que estão submetidas. Vale ressaltar que escola é lugar de alegria, conhecimento, troca de saberes e valorização do ser humano. É um espaço privilegiado onde as crianças gostam de estar.

Nesse debate proposto para a construção do currículo de dimensão intercultural do Nossa Rede, não se trata apenas de mudar o conteúdo programático e focar o processo cognitivo, mas de promover, a partir da sala de aula, mudanças de atitudes em decorrência do reconhecimento de diferenças e diversidades étnicas e culturais. Infere-se assim que o ensino escolar necessita ser fortalecido como formador de consciências críticas e cidadãs.

O Referencial Curricular da Rede Municipal de Salvador para os ensinos infantil e fundamental foi elaborado com cuidado e responsabilidade pelos profissionais do Grupo de Trabalho Nossa Rede Educação Infantil. A Secretaria Municipal da Educação (SMED) realizou a revisão deste documento em parceria com a Fundação Lemann, instituição que contribui com iniciativas de grande impacto para o aprendizado na área da Educação. 
Considerado um referencial de qualidade, este documento está pautado nas necessidades e características de crianças e de grupos específicos de crianças. Deve se ancorar na crença de que, as crianças aprendem melhor quando têm o apoio do adulto ou dos companheiros para desenvolver suas capacidades individuais, o que torna visível para todos o quanto as interações favorecem e potencializam seu desenvolvimento.

Toda instituição de ensino que tenciona desempenhar com eficiência seu processo educativo busca elaborar seu Projeto Político Pedagógico que tem como objetivo principal organizar o trabalho pedagógico da escola como um todo. No âmbito de cada escola, educadores, funcionários, alunos, pais e comunidade local, juntos, assumem responsabilidades para multiplicar esforços na concretização dos objetivos propostos.

O Referencial Curricular do Nossa Rede visa a construção de uma sociedade consciente de seu papel, em relação à política, ao ambiente, aos valores que envolvem justiça, respeito e cooperação, uma sociedade que se centra no homem e na vida, sem preconceitos ou discriminação, pautada em princípios éticos de convivência, que permite igualdade de condições e promove a justiça.

É importante ressaltar que uma proposta curricular é caracterizada pela flexibilidade, podendo sofrer novas mutações de acordo com as circunstâncias e contingências ocasionadas pela fluidez do tempo. A educação não é estática, está sempre em processo de evolução, sujeita às eventualidades do tempo e das gerações.

\subsection{Os Cadernos Pedagógicos de Matemática e Língua Portuguesa}

O Referencial Curricular Municipal para a Educação Infantil de Salvador expresso nos Cadernos Pedagógicos das diferentes disciplinas, elaborados de forma participativa, estabelece parâmetros em relação aos conteúdos fundamentais a serem trabalhados com todos os alunos da Educação Básica da Rede Municipal de Salvador.

Os Cadernos de Língua Portuguesa e Matemática, que orientam as disciplinas básicas da educação, trazem uma mudança na forma de ver os conteúdos e focam na progressão da aprendizagem. A ideia é fortalecer as orientações curriculares de Língua Portuguesa e Matemática trazidas pelos Cadernos Pedagógicos, além de fomentar a discussão de uma política permanente 
de acompanhamento na rede municipal de ensino. Como a proposta tem um caráter formativo as escolas acompanhadas passam a ser chamadas de "Escolas Formadoras".

Os Cadernos Pedagógicos têm profunda ligação com as características culturais e sociais de Salvador, tornando os conteúdos muito próximos da realidade dos alunos. São cuidadosamente construídos a partir de conceitos como representatividade, baianidade, questões étnico-raciais, inclusão, empoderamento, proximidade e diálogo, dentre outros. Contém atividades inclusivas, oportunizando que as crianças com necessidades especiais sejam contempladas. Para os jovens, as atividades são gamificadas, ou seja, utilizam a tecnologia, linguagem e design dos jogos.

Outra inovação nos Cadernos é a aplicabilidade das sequências didáticas. Trata-se de uma nova metodologia de ensino que trabalha os conteúdos de forma transversal, interdisciplinar, abrangendo questões importantes, urgentes e presentes sob várias formas na vida cotidiana, o que proporciona um aprendizado mais amplo e conectado. As sequências didáticas são cíclicas, não se esgotam, e indicam um olhar generoso para as crianças, que são acolhidas seja qual for a situação de aprendizagem em que estejam. É possível revisitar os conhecimentos sempre que for necessário.

Considerando esta proposta inovadora do Projeto Nossa Rede, questionase: "Como os Cadernos Pedagógicos de Língua Portuguesa e Matemática estão ajudando os meninos e meninas de Salvador a aprimorar os seus conhecimentos?". Para responder a esta questão, foi criada uma nova frente de trabalho composta por 12 (doze) escolas da cidade que foram acompanhadas diretamente por uma equipe formada por representantes da SMED, do ICEP e pelas Gerências Regionais de Ensino (GREs).

Patrícia Sadovsky, doutora em Didática da Matemática e professora da Faculdade de Ciências Exatas e Naturais da Universidade de Buenos Aires (UBA), assim declara a respeito da elaboração dos conteúdos de Matemática:

\begin{abstract}
Antes, a expectativa era aplicar mecanicamente coisas já sabidas, sem questionar. Nesta perspectiva que propomos, o objetivo é fomentar o processo de produção matemática, para que a criança saiba por que razão resolver de tal maneira, por que usar tal procedimento, explorando suas estratégias pessoais. Nesse sentido, sim, é possível contribuir para formar estudantes críticos nas aulas de Matemática (NOSSA REDE, 2017, [s.p]).
\end{abstract}

Para os docentes, os Cadernos Pedagógicos têm caráter formativo, com orientações didáticas para as sequências propostas, comentários sobre as 
atividades, indicações de como gerir o tempo em sala de aula e sugestões para ampliar o conhecimento sobre os conteúdos. Os alunos da rede aprenderão a partir das identidades culturais de Salvador.

Ensinar Matemática é desenvolver o raciocínio lógico, estimular o pensamento independente, a criatividade e a capacidade de resolver problemas. Os educadores devem criar condições para que a Matemática seja motivo de instigação, oferecer estímulos, permitir aos alunos criar, explorar, inventar seu próprio modo de expressão e de relação com o mundo, e estar atentos às suas descobertas.

As ideias matemáticas devem ser trabalhadas de forma lúdica, fazendo com que o aluno sinta-se à vontade para operar e construir sua noção de número. Para isso, é necessário que o aluno possa manusear, sentir, usar todos os órgãos dos sentidos a fim de apropriar-se de conhecimentos já obtidos no seu cotidiano.

Entende-se que a preocupação da escola é a de fazer com que o educando participe do seu grupo ativa e afetivamente, apropriando-se de forma significativa de valores, crenças, conhecimentos acadêmicos e referenciais sócios históricos, tornando-se uma pessoa consciente e responsável pela transformação de si mesmo e da realidade na qual está inserido.

Os Cadernos de Matemática foram elaborados para provocar o sentimento de identificação nos alunos. É uma inovação que leva a entender que o cotidiano dos alunos deve ser considerado na escola. A didática projetada nesses Cadernos, por exemplo, é que as aulas possam tomar jeito de exploração científica. Para isso, antes de apresentar os conteúdos tradicionais das operações matemáticas, como subtração ou divisão, os professores estimulam os alunos para que desenvolvam suas próprias estratégias de resolução e interajam com os colegas a fim de juntar pistas do caminho mais eficiente.

É importante que as aulas de Matemática formem crianças autônomas, que possam desenvolver suas próprias estratégias na resolução de problemas. Neste cenário, o papel do professor é interagir com a criança, pedir para que explique como chegou àquele resultado. Não é só resolver a questão, mas, sobretudo, argumentar. Nesse sentido, é possível contribuir para formar estudantes críticos nas aulas de matemática.

No meio acadêmico e profissional, discussões estão sendo levantadas a respeito da situação de muitas crianças que passam de ano sem saber ler e escrever, o que dificulta a aprendizagem nos anos sequenciais. $O$ baixo resultado na 
alfabetização reflete em deficiências de ensino que se reproduzem ao longo de toda a vida escolar do estudante.

Segundo Cagliari (2009, p. 149), "tudo o que se ensina na escola está diretamente ligado à leitura e depende dela para se manter e se desenvolver". $\mathrm{O}$ ato de ler é fundamental para o aprendizado de todas as disciplinas escolares. Nesse sentido, é importante que os professores levem os alunos a ler textos, não somente os escritos, mas também aqueles que estão sujeitos a uma interpretação pessoal, como os símbolos, uma figura, um desenho, e saber o que estes estão transmitindo.

A ausência de leitura faz com que as pessoas diminuam sua capacidade de compreensão acerca da realidade, bem como a habilidade de escrever, competências que a maioria dos habitantes de países desenvolvidos desempenham muito bem.

O brasileiro, em geral, não cultua o hábito de ler, atitude que está relacionada a aspectos culturais do país, como o predomínio da oralidade sobre a escrita, a educação tardia da população que tem como consequência a falta de cultura de leitura e a inexistência de incentivo por parte do governo. No entanto, o maior problema que se verifica nos dias atuais está nas mídias: o brasileiro prefere assistir televisão, ouvir rádio, acessar a internet a ler.

Nesta perspectiva, a educação, em geral, depende de um esforço permanente de melhoria da qualidade do trabalho do professor a partir daquilo que ele já faz, o que significa monitorar e formar ao longo do tempo todos os professores em todas as classes. O papel social da escola é formar leitores e escritores autônomos, entretanto a instituição ainda não desenvolve essa tarefa com plenitude.

Cybele Amado, diretora-presidente do Instituto Chapada de Educação e Pesquisa (ICEP), parceira técnica do projeto Nossa Rede, ressaltou que um dos avanços didáticos dos cadernos pedagógicos de Língua Portuguesa é que eles propõem que conteúdos gramaticais sejam analisados dentro do contexto dos textos apresentados aos estudantes, e não de maneira isolada.

O projeto Música na Escola, como incentivo à leitura e à escrita, lançado no dia12 abril de 2019, faz parte desse currículo próprio da rede municipal. A ideia, produzida em parceria com a Associação Pracatum Ação Social (APAS), integra o programa Nossa Rede, que, entre outras ações, é responsável pela construção dos Cadernos Pedagógicos, elaborados com a participação dos professores. Para o "Música na Escola" foram criadas músicas inéditas ou adaptadas do cancioneiro 
popular com relação direta com as sequências didáticas dos Cadernos Pedagógicos de Língua Portuguesa e Matemática, do 1ํa aํano, do Programa Nossa Rede.

O secretário municipal da Educação de Salvador, Bruno Barral, assim ponderou acerca dessa iniciativa:

É um projeto construído especificamente para nossas escolas municipais e que leva para a sala de aula mais um recurso de apoio à aprendizagem. A música é um instrumento forte na memorização e compreensão de conteúdos, ao mesmo tempo que torna a aula mais dinâmica (ACEB, 2017, [s.p.]).

Durante muito tempo, o ensino das diversas disciplinas do currículo, constituía-se, geralmente, em aulas expositivas, com o uso de metodologias e técnicas pedagógicas cansativas e desinteressantes. A Matemática, Língua Portuguesa e demais disciplinas, por exemplo, que concentram o raciocínio lógico, dedutivo e processos de interpretação, causam muito medo entre os alunos, devido à dificuldade que sentem em lidar com interpretação, números e cálculos.

É preciso reverter o ensino centrado em metodologia desprovida de significados para o aluno, e se voltar para um ensino que proponha desafios que motivem a curiosidade e a necessidade de aprender. Expandir o pensamento e raciocínio do aluno consiste no desafio de despertar nele o interesse pela aprendizagem de forma significativa.

O Nossa Rede beneficiará mais de 100 mil alunos que estão na Educação Infantil e Ensino Fundamental I, dando voz para mais de quatro mil professores, 540 coordenadores pedagógicos e 332 gestores escolares que participaram ativamente do processo de elaboração dos Cadernos Pedagógicos.

\section{PERCURSO METODOLÓGICO DA PESQUISA-AÇÃO}

O método utilizado para abordar o tema proposto neste estudo, "OS CADERNOS PEDAGÓGICOS NO PROGRAMA NOSSA REDE: Uma proposta curricular de dimensão intercultural para as escolas públicas de Salvador-BA", foi a pesquisa bibliográfica e a pesquisa-ação, com enfoque qualitativo.

A pesquisa bibliográfica é uma etapa fundamental em todo trabalho científico, pois fornece fundamentação teórica ao trabalho. Consiste no levantamento de dados coletados em livros, leis, teses, dissertações, artigos científicos, e outros. Segundo Gil (2019) a pesquisa bibliográfica é elaborada com base em material já publicado. 
A pesquisa-ação é muito usada em projetos de pesquisa educacional, com forte potencial de contribuição em processos de transformação das práticas institucionais. A sua utilização como forma metodológica possibilita aos participantes condições de investigar sua própria prática de uma forma crítica e reflexiva. Pimenta (2005) considera que na pesquisa-ação os sujeitos envolvidos em determinada problemática constituem um grupo com objetivos comuns, no qual assumem papéis diversos, inclusive o de pesquisadores.

$\mathrm{Na}$ forma de tratar o objeto da pesquisa, optou-se pela abordagem qualitativa por permitir a subjetividade do pesquisado e a percepção do pesquisador em relação ao tema discutido. Na pesquisa qualitativa, "o ambiente natural é a fonte direta para coleta de dados e o pesquisador é o instrumento-chave". (SILVA; MENESES, 2001, p. 20). A pesquisa qualitativa preocupa-se, portanto, com aspectos da realidade que não podem ser quantificados, centrando-se na compreensão e explicação da dinâmica das relações sociais.

Estes métodos foram escolhidos para a efetivação desta pesquisa, porque dão um subsídio maior ao estudo, pois são realizados em campo, onde se utilizam entrevistas, observações e registro de dados, dando maior qualidade à discussão, abordando o fenômeno em estudo a partir dos sujeitos envolvidos.

$\mathrm{Na}$ tentativa de elucidar os questionamentos levantados e discutidos na construção do Referencial Curricular para o ensino fundamental das escolas públicas de Salvador, formulou-se a seguinte problemática: "Quais propostas pedagógicas de dimensão intercultural ancoram o trabalho desenvolvido pelos educadores da rede municipal de Salvador a partir do uso dos Cadernos Pedagógicos?".

Ante o exposto, o objetivo geral deste trabalho consiste em avaliar o impacto da implantação do Programa Nossa Rede no que tange à ampliação dos conteúdos programáticos comuns a cada área do conhecimento e ano de escolaridade, cujas estruturas cognitivas e atividades experienciais concebam uma proposta curricular de dimensão intercultural que contribua para as crianças aprenderem de maneira prazerosa, crítica e significativa.

As autoras deste estudo, filhas naturais da Bahia e atuando com esmero pela educação de seu estado, reconhecido nacionalmente por sua diversidade cultural, realizaram esta pesquisa-ação com o propósito de ajudar no processo de pensar, agir, refletir, avaliar, e assim aprimorar as práticas pedagógicas que apontem alternativas para a melhoria do processo de ensino e aprendizagem do ensino 
fundamental, valorizando, sobretudo, a realidade sociocultural do povo baiano.

A pesquisa-ação é, portanto, um procedimento reflexivo, sistemático, controlado e crítico, orientada para a resolução de problemas situacionais e específicos, movida sempre pelo desejo de mudança, de transformação, de melhoria de uma realidade educacional e/ou social.

O Projeto Pedagógico Nossa Rede do Ensino Fundamental teve início com a realização do I Seminário Municipal de Educação, promovido pela Secretaria Municipal de Educação (SMED), realizado no dia 26 de setembro de 2015. O evento contou com a participação de mais de três mil educadores e de organizações referência em educação como a Avante - Educação e Mobilização Social e o Instituto Chapada de Educação e Pesquisa (ICEP).

Antônio Nóvoa, professor catedrático do Instituto de Educação da Universidade de Lisboa e ex-reitor da mesma instituição, 61 anos, veio a Salvador por ocasião desse Seminário, para se reunir com exclusividade com os educadores da rede municipal Este educador discorreu sobre o tema "Por uma escola centrada na aprendizagem: tempos, espaços e saberes", alertando os presentes para as "modas que não servem para nada" e para as falsas dicotomias em educação. "Conta mais o conteúdo ou a forma? Autoridade ou liberdade? Mérito ou Igualdade?" Inspirado em Guimarães Rosa, um dos seus escritores favoritos, propôs que seguissem pela "terceira margem do rio", centrada no próprio percurso das crianças. "A aprendizagem é esta terceira margem. É o elemento central da escola".

Nóvoa lançou mão de uma bela metáfora. "Educar é dotar a criança de um meio de transporte para que possa fazer uma viagem mais longa. A aprendizagem é este carro para que ela vá o mais longe possível. Sem isso, ela só chegaria aonde levam seus pés". O professor defendeu que para fazer frente às mudanças no modo como as crianças aprendem hoje, causadas pela revolução digital, é preciso revolucionar também a escola, com foco na "cooperação" entre alunos (uns aprendem com os outros); na "colegialidade" entre os professores (todos cuidam de todos os alunos); e maior colaboração com a sociedade. Desse modo, a escola precisa estar sintonizada com as transformações que estão acontecendo no mundo do conhecimento, do trabalho e da cultura, promovendo mudanças no currículo e na forma de socializar o conhecimento.

Em 2017, foi dada continuidade à construção do Projeto Pedagógico do Nossa Rede, em parceria com o Instituto Chapada que, coletivamente, conseguiu traduzir a identidade e os princípios pedagógicos da Rede Municipal de Ensino. 
Foram realizados, no período, 63 encontros com 2.800 pessoas envolvidas, entre professores de Língua Portuguesa e Matemática, diretores, vice-diretores e coordenadores pedagógicos com 56 horas de formação sem prejuízo do tempo pedagógico dos estudantes. Segundo Nóvoa (2009, p. 16), a formação abarca três dimensões: a pessoal, a profissional e a organizacional. Esse tripé merece especial atenção na formulação e implementação de programas de formação continuada na rede municipal de Salvador.

A Secretaria Municipal da Educação (SMED) realizou no dia 20 de setembro de 2018, na Casa do Comércio, o Seminário Nossa Rede Educação Infantil. O objetivo do evento foi o fortalecimento dos processos formativos voltados à Educação Infantil, bem como a implementação desses processos nas instituições comunitárias conveniadas com a Secretaria. Estiveram presentes ao evento, as gerentes de gestão escolar, Nilce Gama, e de currículo, Edna Rodrigues, ambas da SMED, e a presidente da ONG Avante - Educação e Mobilização Social, Maria Thereza Oliva Marcílio.

A apresentação do projeto "Formação de Formadores" foi feita por Mônica Sâmia, coordenadora do trabalho, que assim pontuou:

\begin{abstract}
O que eu trago com essa fala, com esse diálogo, é sensibilizar e oferecer alguns aportes a esses gestores para o olhar que importa na escola, na creche, no centro de educação. Chamar a atenção para o olhar para a criança, para o gesto, a forma que a criança aprende ouvindo. Essa é uma parte essencial do processo formativo: sensibilizar os adultos, gestores, para essa forma singular da criança ser e funcionar, porque nós que estamos a serviço delas e temos papel fundamental no futuro delas.
\end{abstract}

Os temas apresentados foram: "Relações, espaços e tempos de qualidade na educação infantil", ministrado por Leila Oliveira, especialista em educação, consultora pedagógica e integrante da Rede Pikler no Brasil; e o "Projeto curricular no chão da escola: possibilidades e desafios no âmbito da gestão", apresentado por Maria Thereza Oliva Marcílio, que assim ponderou:

\footnotetext{
É importantíssimo o gestor se reconhecer como parte de um conjunto que toma decisões e que essas decisões devem compreender o bem estar das crianças a aprendizagem e o desenvolvimento delas. Então, é importante que o gestor se comprometa com o chão da sala e seja um interlocutor crítico e criativo para o órgão central (PORTAL EDUCAÇÃO, 2018, [s.p.]).
}

Visando à consolidação do Sistema Próprio de Ensino Municipal e a Formação dos Educadores as palestras trouxeram uma temática recorrente na prática das organizações, dos espaços e do tempo para acolher as crianças pequenas de forma mais sensível. Nilce Gama, gerente de gestão escolar da SMED, assim observou: "É um momento único, de sensibilização para um trabalho que 
requer muita disponibilidade, afeto e cuidado com as nossas crianças de 0 a 3 anos" (ibidem).

O evento teve dois momentos, pela manhã a roda de diálogos foi voltada para colaboradores da SMED, gerentes regionais e gestores das instituições de Educação Infantil. $\mathrm{Na}$ parte da tarde, a roda de diálogos foi voltada para as instituições comunitárias parceiras da SMED. Estiveram presentes na composição da mesa, a diretora pedagógica da SMED, Joelice Braga, a presidente do Conselho Municipal de Educação, Lindalva Amorim, e Ana Luíza Burato, consultora e sóciafundadora da Avante. Durante a roda de diálogos da tarde, a palestrante Lívia Oliveira mostrou através de vídeos como se desenvolvem as crianças nessa faixa etária e da importância de preservar o tempo, o espaço e de como esse cuidado pode reverberar de forma positiva, assim afirmando:

A gente tem pensado que a sensibilização dos educadores tem sido muito baseada em questões externas. Eu tentei trazer um pouco de como as crianças sentem tudo isso, como elas balizam os tempos, as relações e os espaços, como é que as crianças sentem tudo isso. Então eu acho que a ideia é sensibilizar mobilizar para entender a força da criança (PORTAL EDUCAÇÃO, 2018, [s.p.])..

Edna Rodrigues, gerente de currículo da SMED, afirmou que esse foi o primeiro passo para outras formações:

É o início de uma grande formação que está chegando na Rede Municipal,
alinhando o pedagógico das Escolas Comunitárias conveniadas com o
Programa Nossa Rede, iniciando pelas creches, grupo ( 0 a 3), e que se
estenderá, até 2019 , para as turmas da pré escola (4 e 5 anos). A presença
dos gestores, coordenadores das escolas, creches e dos CMEls nessa roda
de diálogo é muito importante (Ibidem).

As formações iniciaram-se no mês de dezembro de 2019 com a presença de Diretores Escolares, Técnicos da Secretaria da Educação e das Gerências Regionais - GRs, e Coordenadores Pedagógicos do Ensino Fundamental. A ação pretende mobilizar os diversos atores na implantação dos documentos visando impactar positivamente nos resultados de aprendizagem dos alunos.

A construção do material para os anos finais foi feita de julho a dezembro de 2018. A iniciativa envolveu 930 profissionais da educação pública municipal, entre professores, gestores e coordenadores. Um diferencial importante foi a participação de 240 alunos na produção dos Cadernos Pedagógicos, que dialogam com os alunos desta faixa etária, tornando o material mais atrativo e interessante.

O lançamento dos materiais complementares foi feito durante o "Seminário Municipal Nossa Rede: A consolidação de uma política educacional", realizado no dia 15 de abril de 2019, no Hotel Fiesta, no Itaigara. O evento teve as presenças do 
prefeito ACM Neto; do vice-prefeito e secretário municipal de Infraestrutura e Obras Públicas (SEINFRA), Bruno Reis; do secretário municipal da Educação (SMED), Bruno Barral; e da presidente do Instituto Chapada de Educação e Pesquisa (ICEP), Elisabete Monteiro, além de gestores das unidades municipais de ensino.

O Seminário representou o encerramento do ciclo de produção dos materiais próprios da rede municipal, iniciado em 2015, que passa a ter todas as etapas contempladas: Educação Infantil (pré-escola) e Ensino Fundamental - Anos Iniciais (1 ao 5o ano) e Anos Finais ( $6^{\circ}$ ao 9a ano). A rede municipal de ensino de Salvador passou a ter no primeiro semestre de $2019,100 \%$ do material didático produzido com conteúdo próprio, cuja iniciativa é inédita no Brasil.

\section{RESULTADOS E DISCUSSÃO}

Para a análise e discussão dos dados foi utilizada a técnica de análise de conteúdo, evidenciando os dispositivos legais determinados pela Lei 9.394, de 20 de novembro de 1996; pela Lei 10.639, de 9 de janeiro de 2003, e pela Lei 11.645, de 10 de março de 2008. Bauer e Gaskell (2008) esclarecem que os textos escritos são os mais utilizados na análise de conteúdo, podendo ser dialogados pelo pesquisador na tentativa de responder aos questionamentos da pesquisa.

Os resultados discutidos neste estudo ampliam a capacidade de compreensão dos professores acerca de suas práticas pedagógicas, favorecendo amplamente às mudanças, e promovendo a visão de conjunto para a tomada de consciência de todos os envolvidos. As aprendizagens esperadas para os alunos do Ensino Fundamental I foram relacionadas em uma tabela demonstrativa abaixo exibida, adaptada pelas autoras desta pesquisa, tendo como parâmetros o Ensino de História, disciplina que elenca as questões étnico-raciais. 
Tabela 1 - Aprendizagens esperadas no Ensino de História

\begin{tabular}{|c|c|c|c|c|}
\hline & 20 ano & $3^{\circ}$ ano & $4^{\circ}$ ano & $5^{\circ}$ ano \\
\hline $\begin{array}{l}\text { Compreender } \\
\text { os dias da } \\
\text { semana, a } \\
\text { noite e o dia e } \\
\text { as atividades } \\
\text { desenvolvidas } \\
\text { pela criança e } \\
\text { sua família. } \\
\text { Identificar as } \\
\text { ocupações da } \\
\text { criança em } \\
\text { casa e na } \\
\text { escola. } \\
\text { Identificar as } \\
\text { profissões dos } \\
\text { familiares e } \\
\text { relação delas } \\
\text { com o bairro, } \\
\text { a cidade e o } \\
\text { contexto onde } \\
\text { vive. } \\
\text { Compreender } \\
\text { sua relação } \\
\text { com o bairro e } \\
\text { a cidade. } \\
\text { Identificar a } \\
\text { passagem do } \\
\text { tempo (ano, } \\
\text { meses, } \\
\text { semanas, } \\
\text { dias). }\end{array}$ &  &  & $\begin{array}{l}\text { Compreender } \\
\text { a formação } \\
\text { inicial da } \\
\text { Bahia e do } \\
\text { Brasil. } \\
\text { Compreender } \\
\text { a expansão } \\
\text { do território } \\
\text { brasileiro. } \\
\text { Relacionar a } \\
\text { história da } \\
\text { cidade com a } \\
\text { história do } \\
\text { país e de } \\
\text { outros povos. } \\
\text { ldentificar e } \\
\text { entender a } \\
\text { Bahia na } \\
\text { Colônia. } \\
\text { Refletir } \\
\text { criticamente } \\
\text { sobre o papel } \\
\text { da Bahia na } \\
\text { independência } \\
\text { do Brasil. }\end{array}$ & 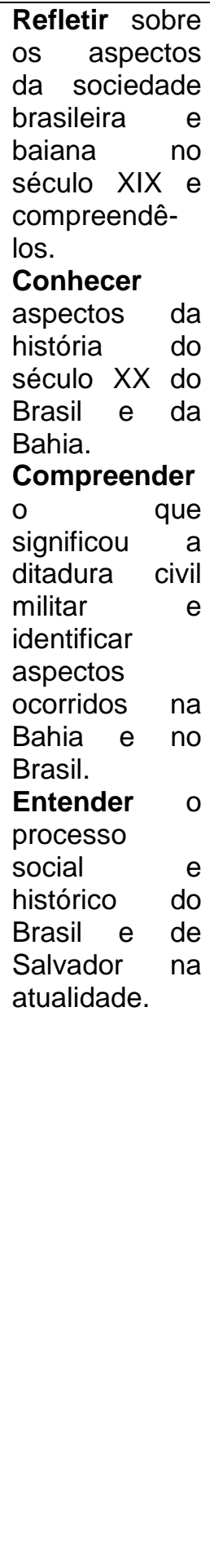 \\
\hline
\end{tabular}

Fonte: Referencial Curricular Municipal para a Educação Infantil de Salvador, 2015. Adaptada pelas autoras da pesquisa (2020).

Com base nos objetivos acima referenciados propõe-se a realização eficaz de mudanças nos sistemas educacionais enquanto espaços monoculturais, através do desenvolvimento de atitudes, projetos curriculares e ideias pedagógicas, que sejam sensíveis à emergência do multiculturalismo. É importante partir de temas que 
se relacionem ao interesse dos alunos no dia a dia. Assim, o Projeto Pedagógico Nossa Rede parte do pressuposto de que a aprendizagem é sempre relacional, isto é, os alunos aprendem relacionando novas informações a conhecimentos anteriores, pois somente assim elas ganham sentidos, sem os quais não ocorre aprendizagem.

O bom desempenho do processo ensino-aprendizagem requer, inicialmente, que os educadores tenham conhecimento das necessidades, diferenças e dificuldades de cada aluno para assim criar e desenvolver estratégias diferenciadas capazes de efetivar seu sucesso, sua promoção.

Para tanto, é importante tomar as estratégias de produção de conhecimento como objeto de ensino e investir no cultivo de virtudes intelectuais, como a valorização da dúvida, a construção de problemas desafiadores, a criatividade, o reconhecimento e a valorização do conhecimento produzido, a investigação rigorosa, dentre outras, como elementos centrais da formação.

A Lei de Diretrizes e Bases da Educação (LDB) determina que é responsabilidade das escolas elaborarem seus currículos. Aprovada em 1996, a LDB preocupou-se como o currículo e os educadores deveriam se adaptar às novas exigências educativas, oportunizando, à época, o debate sobre a etnicidade e diversidade cultural na sociedade nacional ao destacar a igualdade de direitos e a equidade. Assim, instituiu no parágrafo $2^{\circ}$, do artigo Art. 24, que: "O ensino da História do Brasil levará em conta as contribuições das diferentes culturas e etnias para a formação do povo brasileiro, especialmente das matrizes indígena, africana e europeia" (BRASIL, 1996, [s.p.]).

Para a comunidade negra e demais movimentos sociais as afirmações oficiais de reconhecimento da desigualdade social e racial e as medidas para o combate da discriminação, sobretudo, a mudança no ensino da História do Brasil foi um ganho. As novas orientações historiográficas além de ensejarem um ensino mais crítico e noções de cidadania, favoreceram a proposição de eixos temáticos, que privilegiaram grupos até então ausentes nos conteúdos dos manuais didáticos, como mulheres, crianças, negros, ou seja, as "falsas minorias".

Como resposta, foram criados os Temas Transversais nos Parâmetros Curriculares Nacionais (PCNs) que propunham o estudo de grupos sociais que convivem no território nacional, as desigualdades socioeconômicas e a crítica às relações sociais discriminatórias excludentes que permeiam a sociedade brasileira, oferecendo ao aluno a possibilidade de conhecer o Brasil como um país complexo, multifacetado e, algumas vezes, paradoxal. Questões relativas ao ensino, à 
aprendizagem e ao seu conteúdo agregam às propostas tradicionais, novos temas, novas questões e abordagens relativas à identidade étnico racial e cultural.

A Lei expressa a vontade popular, mas é parte e não fim do trabalho. Para que não vire "letra morta" é preciso refletir não apenas sobre os pressupostos históricos e sociológicos, mas também sobre a necessidade de ressignificação cultural. Nesse sentido, é preciso reconsiderar o processo escolar de ensinar e aprender refletindo sobre sua dimensão cognitiva e ética, uma vez que conceitos históricos geram valores que orientam a vida cotidiana.

Para Cortesão (2001), a prática atenta às problemáticas interculturais está ainda muito longe de ser consolidada no sistema educativo. A escola deve sempre adotar uma atitude construtiva face a esta realidade, desenvolvendo práticas positivas de educação, permitindo a criação de um espaço que favoreça a expressão de cada um, nos seus diferentes componentes - linguagem, valores, quadros de referência, e outros, desenvolvendo estratégias que conduzam à anulação da discriminação.

A Lei 10.639/2003 altera a Lei 9.394/1996, para incluir no currículo oficial da rede de ensino a obrigatoriedade do ensino de "História e Cultura Afro-Brasileira e Africana" estimulando a necessidade de reflexão não apenas do ponto de vista temático, mas também sobre as representações que amparam posicionamentos cotidianos. Contudo, a criação desta lei não pode, por si só, ter efeito e demandará ações que garantam a sua efetividade.

Segundo as novas orientações, a escravidão no Brasil que tinha anteriormente a ênfase no 'escravo', genericamente designado no quadro econômico, desloca-se e agrega ao estudo as suas origens, culturas, e outras contribuições. O escravo passa a ter rosto, ou melhor, uma multiplicidade de rostos.

A Lei 11.645/2008 altera a Lei 9.394/1996, modificada pela Lei 10.639/2003, para incluir no currículo oficial da rede de ensino a obrigatoriedade da temática "História e cultura afro-brasileira e indígena". É importante refletir sobre o tipo de imagem e informação que projetaram e projetam, quando se contraria a historiografia recente afirmando-se que africanos eram trazidos para o Brasil porque indígenas não estavam adaptados ao trabalho. A generalização desta afirmativa recusa a diversidade de experiências e debates.

Aprovadas como consequência, sobretudo, da pressão da sociedade civil, é notório o reconhecimento de que a Lei 10.639/2003 e a Lei 11.645/2008 ainda não são plenamente aplicadas. Nesta perspectiva, o presente artigo considera que os 
debates ocorridos no Brasil sobre a questão do negro e do índio na sociedade nacional chegam, sim, à escola, embora não necessariamente tal como foram propostos.

Nessa perspectiva, a escola será mais competente se for capaz de valorizar a diferença. É interessante ressaltar que valorizar a diferença não significa exaltar a desigualdade. Diferença é um conceito cultural e desigualdade é um conceito ético. Homens e mulheres, brancos e negros, brasileiros e estrangeiros são todos diferentes, mas jamais desiguais.Considerando a escola um espaço de socialização, a formação de um programa curricular que aborde a questão da opressão ensina aos alunos a não terem preconceitos e discriminações. O multiculturalismo crítico ou de resistência é o que está mais voltado aos anseios dos movimentos multiculturais, conforme Silva e Bradim (2008, p. 64):

Conceber, enfim, o multiculturalismo numa perspectiva critica e de resistência pode contribuir para desencadear e fortalecer ações articuladas a uma pratica social cotidiana em defesa da diversidade cultural, da vida humana, acima de qualquer forma discriminatória, preconceituosa ou excludente.

Sob a ótica das análises educacionais, a manifestação do multiculturalismo, traz desafios essenciais às investigações sobre o conhecimento, abrindo possibilidades para se pensar em práticas curriculares voltadas à construção das identidades de discentes e docentes, multiculturalmente, comprometidas com o ensino/aprendizagem, visando promover o respeito à diferença e à pluralidade cultural.

O que advém das propostas aqui elencadas é que a educação não é apenas uma transmissão de conteúdos entre professor e aluno, mas sim um diálogo entre estes sujeitos, onde todos estão em um ambiente de constante aprendizado. Destaca-se a necessidade deste trabalho ser desenvolvido de forma interdisciplinar, pois o envolvimento de todos os educadores ajuda o aluno a desenvolver um olhar crítico, promovendo sua cidadania. É preciso reconhecer a importância de pensar o currículo da escola básica com base na integração das diversas áreas de conhecimento.

\section{CONSIDERAÇÕES FINAIS}

Os resultados obtidos nesta pesquisa bibliográfica e pesquisa-ação, com abordagem qualitativa, revelaram que a proposta curricular do Nossa Rede é interessante e envolvente, pois centraliza a ação educativa no aluno, na sua 
aprendizagem, na sua promoção, considerando suas necessidades e expectativas. Entretanto, pelo fato de configurar-se como uma ação pedagógica inovadora faz-se necessário pesquisas e estudos constantes para apoio à prática pedagógica..

Segundo o Sistema de Avaliação da Educação Básica (SAEB), avaliação diagnóstica desenvolvida pelo Ministério da Educação (MEC), Salvador tem conquistado avanços constantes no Índice de Desenvolvimento da Educação Básica (IDEB), destacando-se como a capital que mais avança em educação. Entre 2013 e 2017, o município registrou crescimento superior a 30\% no índice, tanto nos anos iniciais quanto nos anos finais. Esses avanços são reflexos das políticas adotadas pela Prefeitura e que têm revolucionado a educação em Salvador: aumento de investimentos, melhorias físicas das escolas, construção de material pedagógico próprio, dentre outras conquistas.

A pretensão desta pesquisa é fazer com que cada profissional que atua na área da Educação Infantil ao ler este artigo, reflita sobre sua prática educativa, se está de acordo com a realidade e necessidades das crianças. Neste contexto, faz-se necessário, continuamente, (re)pensar o trabalho pedagógico, refazer objetivos, rever conteúdos e buscar metodologias que sejam adequadas à formação que hoje é exigida pela sociedade.

Conclui-se que através da articulação entre gestores, coordenadores pedagógicos e professores na discussão do planejamento, objetivos, expectativas e metas a serem alcançados, o currículo das escolas municipais de Salvador possa atingir o objetivo maior da educação que é a formação integral do ser humano. Educar pressupõe transformar-se.

\section{REFERÊNCIAS:}

AUSUBEL, D. P. A aprendizagem significativa. São Paulo: Moraes, 1982.

BAUER, M.; GASKELL, G. (Eds.). Qualitative researching with text, image, and sound. London: Sage, 2008.

BRASIL, Lei. 10.639, De 9 de Janeiro, de 2003. Disponível em: http://www. planalto. gov. br/ccivil_03/leis/2003/10. Acesso em 20 ago. 2020. v. 639, 2003.

BRASIL, Senado Federal. Lei de Diretrizes e Bases da Educação Nacional: $\mathbf{n}^{\circ}$ 9394/96. Brasília,MEC/SEMTEC. 1996.

BRASIL. Diretrizes Curriculares Nacionais Gerais da. Educação Básica. Brasília: MEC/SEF, 2013. 
BRASIL. Secretaria de Educação Fundamental. Parâmetros Curriculares Nacionais: terceiro e quarto ciclos: apresentação dos temas transversais. Brasília: MEC/SEF, 1998.

BRASIL. SECRETARIA DE EDUCAÇÃO FUNDAMENTAL. Parâmetros Curriculares nacionais: terceiro e quarto ciclos: apresentação dos temas transversais. Brasília: MEC/SEF, 1998.

CAGLIARI, L. C.. Alfabetização \& Linguística. São Paulo: Scipicione, 2009.

CHERVEL, A. História das disciplinas escolares: reflexões sobre um campo de pesquisa. Teoria \& educação, v. 2, n. 2, p. 177-229, 1990.

CORTESÃO, L. Acerca da ambiguidade das práticas multiculturais: necessidades de vigilância crítica hoje e amanhã. Educação e diferença: valores e práticas, 2001.

DA SILVA, M.J.A; BRANDIM, M.R.L. Multiculturalismo e educação: em defesa da diversidade cultural. Diversa, v. 1, p. 51 citation_lastpage= 66, 2008.

D' ADESKY. Jacques. Pluralismo étnico e multi-culturalismo: racismo e antirracismo no Brasil. Rio de Janeiro, Pallas, 2001.

EDUCAÇÃO, Da. Lei no 9.394, de 20 de dezembro de 1996. Estabelece as diretrizes e bases da. FREIRE, Paulo. Pedagogia do oprimido. rev. e atual. Rio de Janeiro: Paz e Terra, p. 95-101, 2011.

GADOTTI, M. Perspectivas atuais da educação. Porto Alegre, Ed. Artes Médicas, 2000.

GIL, A.C. Como elaborar projetos de pesquisa. 6. ed. São Paulo: Atlas, 2019.

GLOBO.COM G1 BA. Uma em cada 5 pessoas na Bahia se declara preta, aponta IBGE. Disponível em: <https://g1.globo.com/ba/bahia/noticia/2019/05/22/uma-emcada-5-pessoas-na-bahia-se-declara-preta-aponta-ibge.ghtml>. Acesso em 15 jul. 2020.

LEI № 7791, de 26 de janeiro de 2010. Institui o Plano Municipal de Educação PME no município de Salvador e dá outras providências. Salvador, 2010.

LEI, №. 11.645, de 10 de março de 2008. Altera a Lei, n. 9.394. Brasília: MEC/SEF, 2008.

MOREIRA, M. A. Aprendizagem significativa crítica. Porto Alegre: Instituto de Física, UFGRS. 2005. 297 História e Perspectivas, Uberlândia (42): 285-313, jan.jun.2010.

NOVAK, J. D.; GOWIN, D. B. Aprender a aprender. Lisboa: Plátano Edições. Técnicas. Tradução de Learning how to learn.(1984). 1996.

NÓVOA, A. Imagens do futuro presente. Lisboa: Educa, 2009. 
PIMENTA, S.G. Pesquisa-ação crítico-colaborativa: construindo seu significado a partir de experiências com a formação docente. Educação e pesquisa, v. 31, n. 3, p. 521-539, 2005.

SALVADOR. Referencial curricular municipal para a educação infantil em Salvador. Salvador: Secretaria Municipal da Educação, 2015.

DA SILVA, M.J.A; BRANDIM, M.R.L. Multiculturalismo e educação: em defesa da diversidade cultural. Diversa, v. 1, p. 51 citation_lastpage= 66, 2008.

SILVA, E.L; MENEZES, E.M.. Metodologia da pesquisa e elaboração de dissertação. 2001.

VYGOTSKY, L.S. A formação Social da mente (Trad.) São Paulo: [s.I.] 1998. 